\title{
Treatment of the low bone mineral density with intravenous pamidronate in pediatric patients: review of a protocol of a single-day infusion twice a year S Ricart*, J Anton, M del Rio and J Ros
}

Address: Hospital Sant Joan de Déu, university of Barcelona, Barcelona, Spain

* Corresponding author

from $15^{\text {th }}$ Paediatric Rheumatology European Society (PreS) Congress

London, UK. 14-17 September 2008

Published: 15 September 2008

Pediatric Rheumatology 2008, 6(Suppl I):PI32 doi:I0.II86/I546-0096-6-SI-PI32

This abstract is available from: http://www.ped-rheum.com/content/6/SI/PI32

(c) 2008 Ricart et al; licensee BioMed Central Ltd.

\section{Background}

On the basis of effectiveness of bisphosphonates in adults, a simple protocol for the treatment of low bone mineral density in children was developed in 1995 in our centre. Objectives: To review the effectiveness of a singleday infusion of pamidronate twice a year in children. Secondary, to describe its efficacy in relation to the etiology of osteoporosis.

\section{Materials and methods}

Retrospective review of patients treated with pamidronate from January 1995 to June 2006 in Sant Joan de Déu hospital (Spain). Patients:younger than 18 years that underwent treatment with the protocol for at least one year and with $\mathrm{z}$-score $<-2.5$, fractures and $\mathrm{z}$-score $<-1$ or documented bone pain with $z$-score $<-1$. They were classified into 4 groups: osteogenesis imperfecta, chronic treatment with steroids, disuse and other conditions. Interventions: single intravenous administration of pamidronate $(30 \mathrm{mg}$ in prepubescent patients and $60 \mathrm{mg}$ in all other patients) every six months. Clinical, radiological data and bone mineral density were obtained basal and after each cycle. For each patient the ratio fractures/year during the treatment and the total increase in $\mathrm{z}$-score (total $\Delta \mathrm{Z}$ ) after the treatment were calculated.

\section{Results}

56 patients were included. Overall, fractures/year decreased from 1.75 basal to 0.46 during the treatment. Osteogenesis imperfecta group had better total $\Delta \mathrm{Z}$ (1.25).
Disuse group had clinical improvement although poor total $\Delta \mathrm{Z}$ increase $(0.12)$.

\section{Conclusion}

There is a clinical improvement in all patients. The OI group has the best gain in bone mineral mass. The protocol is safe, simple and well tolerated by patients and families. 